Fixed Point Theory, 18(2017), No. 1, 37-46

http://www.math.ubbcluj.ro/ nodeacj/sfptcj.html

\title{
MEASURES OF WEAK NONCOMPACTNESS AND FIXED POINT THEORY IN BANACH ALGEBRAS SATISFYING CONDITION $(\mathcal{P})$
}

\author{
AFIF BEN AMAR* AND DONAL O'REGAN** \\ *Faculty of Sciences, Department of Mathematics \\ Sfax University, Sfax, Tunisia \\ E-mail: afif_ben_amar@yahoo.fr \\ ** School of Mathematics, Statistics and Applied Mathematics \\ National University of Ireland, Galway, Ireland \\ Nonlinear Analysis and Applied Mathematics (NAAM)-Research Group \\ Department of Mathematics, King Abdulaziz University \\ Jeddah, Saudi Arabia \\ E-mail: donal.oregan@nuigalway.ie
}

Abstract. The aim of this paper is to prove some new fixed point theorems in a nonempty closed convex subset of a Banach algebra satisfying a sequential condition $(\mathcal{P})$ in a weak topology setting. Key Words and Phrases: Measure of weak noncompactness, quasi-regular, weakly condensing, weakly sequentially continuous, relatively weakly compact, fixed point theorems.

2010 Mathematics Subject Classification: 47H08, 47H09, $47 \mathrm{H} 10$.

\section{REFERENCES}

[1] C. Angosto, B. Cascales, Measures of weak noncompactness in Banach spaces, Topol. Appl., 156(2009), 1412-1421.

[2] R.R. Akhmerov, M.I. Kamenskii, A.S. Potapov, A.E. Rodkina, B.N. Sadovskii, Measures of Noncompactness and Condensing Operators, Birkhäuser, Basel, 1992.

[3] J. Banaś, A. Ben Amar, Measures of noncompactness in locally convex spaces and fixed point theory for the sum of two operators on unbounded convex sets, Comment. Math. Univ. Carolin., 54(2013), no. 1, 21-40.

[4] J. Banaś, J. Rivero, On measures of weak noncompactness, Ann. Math. Pure Appl., 151(1988), 213-224.

[5] J. Banaś, A. Martinón, Measures of weak noncompactness in Banach sequence spaces, Portugal. Math., 59(1995), no. 2, 131-138.

[6] J. Banaś, M.-A. Taoudi, Fixed points and solutions of operators equations for the weak topology in Banach algebras, Taiwanese J. Math., 18 (2014), no. 3, 871-893.

[7] A. Ben Amar, S. Chouayekh, A. Jeribi, New fixed point theorems in Banach algebras under weak topology features and applications to nonlinear integral equations, J. Funct. Anal., 259(2010), no. 9, 2215-2237.

[8] A. Ben Amar, S. Chouayekh, A. Jeribi, Fixed point theory in a new class of Banach algebras and application, Afr. Mat., 24(2013), 725-724. 
[9] A. Ben Amar, A. Jeribi, R. Moalla, Leray-Schauder alternatives in Banach algebra involving three operators with application,, Fixed Point Theory, 15(2014), no. 2, 359-372.

[10] D.W. Boyd, J.S.W. Wong, On nonlinear contractions, Proc. Amer. Math. Soc., 20(1969), 458464.

[11] F.S. De Blasi, On a property of the unit sphere in Banach space, Bull. Math. Soc. Sci. Math R.S. Roumanie., 21(1977), 259-262.

[12] I. Dobrakov, On representation of linear operators on $C_{0}(T, X)$, Czechoslovak Math. J., 21(1971), no. 96, 13-30.

[13] J. Diestel, A survey of results related to Dunford-Pettis property, in Cont. Math. 2, Amer. Math. Soc. of Conf. on Integration, Topology and Geometry in Linear Spaces, 1980, 15-60.

[14] N. Dunford, B.J. Pettis, Linear operations on summable functions, Trans. Amer. Math. Soc., 47(1940), 323-392.

[15] N. Dunford, J.T. Schwartz, Linear Operators: Part I, Intersciences, 1958.

[16] R.E. Edwards, Functional Analysis, Theory and Applications, Holt, Reinhart and Winston, New York, 1965.

[17] A. Grothendieck, Sur les applications linéaires faiblement compactes d'espaces du type $C(K)$, Canad. J. Math., 5(1953), 129-173.

[18] A. Jeribi, R. Moalla, Nonlinear alternatives of Leray-Schauder type in Banach algebra involving four operators with application, Numer. Funct. Anal. Optim., 34(2013), no. 10, 1097-1114.

[19] N. Kaddachi, A. Jeribi, B. Krichen, Fixed point theorems of block operator matrices on Banach algebras and an application to functional integral equations, Math. Meth. Appl. Sci., 36(2013), no. $6,659-673$.

[20] A. Kryczka, S. Prus, M. Szczepanik, Measure of weak noncompactness and real interpolation of operators, Bull. Austral. Math Soc., 62(2000), 389-401.

[21] A. Kryczka, S. Prus, Measure of weak noncompactness under complex interpolation, Studia Math., 147(2001), 89-102.

[22] E. Zeidler, Nonlinear Functional Analysis and Its Applications, Vol. I, Springer, New York, 1986.

Received: February 6, 2014; Accepted: March 27, 2014. 